\title{
Pelayanan antenatal care dalam pengelolaan anemia berhubungan dengan kepatuhan ibu hamil minum tablet besi \\ Subarda ${ }^{1}$, Muhammad Hakimi2 ${ }^{2}$ Siti Helmyati ${ }^{3}$
}

\begin{abstract}
Background: The prevalence of pregnant women with anemia is still one of nutrition problems in Indonesia. The main cause of this case is low iron supplementation compliance as the effect of lack of antenatal care (ANC) services and lack promotion of anemia prevention and iron tablet benefit.

Objective: The study was aimed to know the relationship between ANC services in anemia management with iron supplementation compliance of pregnant women.

Method: The study was observational with cross sectional design. Subjects were 202 pregnant women in the II-III trimester period in Asahan District. Sampling interpretation was randomly performed by choosing 3 sub-districts with $K 4 \geq 85 \%$ and $\leq 85 \%$ coverage. Data collection was carried out by interview based on structured questionnaire and KIA literature study while validity of iron supplementation compliance using stool test. Data analysed using chi-square and logistic regressions test.

Results: The result showed that $41.1 \%$ of pregnant women were complied. Based on chi-square test, there were four significant variables related to pregnant women's compliance namely ANC services (ratio prevalence 1.82; C/95\%: 1.22-2.70), anemia assessment (ratio prevalence 1.79; CI95\%: 1.22-2.64), nutrition consultation (ratio prevalence 1.41; Cl95\%: 1.12-1.76) and knowledge (ratio prevalence 1.42; CI95\%: 1.12-1.79). Meanwhile logistic regressions test showed that the most influencing variable was ANC services (OR 3.125) after controlling knowledge variable.

Conclusion: There were positive relationship between ANC services, anemia assessment, and nutrition consultation with iron supplementation compliance.
\end{abstract}

KEY WORDS ANC services, iron supplementation compliance, pregnant women

\section{PENDAHULUAN}

Prevalensi anemia pada ibu hamil di Indonesia menurut Survei Kesehatan Rumah Tangga (SKRT) tahun 2004 dilaporkan sebesar 50,5\% (1), sedangkan di Provinsi Daerah Istimewa Yogyakarta tahun 2005 mencapai 73,9\% (2), dan di Nusa Tenggara Timur mencapai $80 \%$ (3). Ibu hamil yang mengalami anemia memiliki risiko kematian hingga 3,6 kali lebih besar dibandingkan dengan ibu hamil yang tidak mengalami anemia (4). Anemia juga memiliki kontribusi yang tinggi terhadap kematian di Indonesia dengan persentase mencapai $50-70 \%$ (3). Selain itu, ibu hamil yang menderita anemia dapat berdampak terhadap janin, seperti bayi lahir prematur, risiko bayi berat lahir rendah (BBLR), kelainan janin, serta meningkatnya risiko gawat janin (5). Kegiatan suplementasi besi merupakan penanggulangan anemia yang paling banyak dilakukan, di samping upaya lain seperti fortifikasi bahan makanan dengan zat besi dan pendidikan gizi lewat strategi komunikasi, informasi, dan edukasi (6).

Di Indonesia, pemberian tablet besi kepada ibu hamil sudah dilakukan sejak tahun 1975 dengan melibatkan lintas sektor dan lintas program seperti melalui pengintegrasian ke dalam pelayanan antenatal care (ANC) oleh bidan terhadap ibu hamil. Pelayanan ini hasilnya belum menggembirakan. Menurut hasil Survei Demografi dan Kesehatan Indonesia (SDKI) tahun 20022003 di Provinsi Sumatera Utara dilaporkan hanya 2,1\% ibu hamil yang minum tablet besi dengan jumlah hari 60-89 dan sekitar $34,4 \%$ ibu hamil tidak pernah minum tablet besi. Pelayanan ini secara rutin telah dilaksanakan oleh puskesmas, puskesmas pembantu, rumah sakit umum (RSU), dan klinik-klinik swasta, yaitu dengan cara memberikan tablet tambah darah yang berisi $60 \mathrm{mg}$ ferro dan $0,25 \mathrm{mg}$ asam folat kepada setiap ibu hamil minimal 90 tablet selama hamil (6).

Di Kabupaten Asahan yang terdiri dari 20 kecamatan dan 271 desa telah berdiri 1 unit RSU, 4 unit rumah sakit swasta, 24 unit puskesmas, 172 unit puskesmas pembantu, dan 437 bidan. Dilihat dari jumlah sarana dan jumlah bidan, seharusnya angka anemia ibu hamil tersebut dapat ditekan dengan pemberian tablet besi ibu hamil. Namun demikian, laporan Dinas Kesehatan Kabupaten Asahan tahun 2006 cakupan kunjungan pemeriksaan kehamilan yang keempat (K4) ibu hamil sebesar 85,5\% (masih ada 10 wilayah kecamatan dengan cakupan K4 kurang dari $85 \%$ ) dan cakupan pemberian tablet tambah darah (Fe3) sebesar 82,5\% (7). Hasil cakupan Fe3 ini belum mencapai target yang telah ditetapkan. Menurut hasil survei anemia gizi pada tahun 2004 oleh PT Merck yang bekerja sama dengan Dinas Kesehatan Asahan diketahui sebanyak 39\%

\footnotetext{
1 Dinas Kesehatan Kabupaten Asahan, Jl. Sisingamangaraja No 311, Kisaran, Sumatra Utara 21214, e-mail: barda_subarda@yahoo.com 2 Magister Kesehatan Ibu dan Anak-Kesehatan Reproduksi (KIA-KR) FK UGM, JI. Farmako, Sekip Utara, Yogyakarta 55281, e-mail: moh. hakimi@yahoo.com

${ }^{3}$ Program Studi Gizi Kesehatan FK UGM, JI. Farmako, Sekip Utara, Yogyakarta 55281, e-mail: siti_helmyati@yahoo.com
} 
ibu hamil mengalami anemia. Cakupan K4 dan Fe3 yang cukup tinggi ini belum diimbangi dengan penurunan angka anemia ibu hamil.

Prevalensi anemia besi ibu hamil yang tinggi dapat disebabkan oleh tingkat kepatuhan minum tablet besi yang rendah (20-30\%) (8). Hasil penelitian di Bantul menunjukkan bahwa dengan adanya suplementasi Fe mingguan (sekali seminggu) terjadi peningkatan kepatuhan sebesar $12,1 \%$ dan berpengaruh nyata terhadap nilai kepatuhan sebesar 6,6 kali lebih tinggi bila dibandingkan suplementasi harian setelah dikendalikan dengan faktor pengetahuan, sikap, praktik, umur, pekerjaan, pendidikan, pendapatan, paritas, dan ANC. Frekuensi minum dan jumlah tablet $\mathrm{Fe}$ merupakan faktor dari pasien yang mempengaruhi tingkat kepatuhan. Setelah dilakukan stratifikasi berdasarkan status anemia pada awal penelitian, kenaikan kadar hemoglobin $(\mathrm{Hb})$ pada kelompok mingguan maupun harian menunjukkan tidak ada perbedaan bermakna $(p>0,05)(9)$. Hasil survei kesehatan nasional (Surkesnas) tahun 2004 menunjukkan bahwa kepatuhan minum pil besi makin tinggi seiring dengan makin tingginya pemeriksaan ANC dan meningkatnya sosial ekonomi rumah tangga (10). Berdasarkan hal tersebut, penelitian dilakukan untuk mengetahui peran pelayanan ANC dalam pengelolaan anemia sebagai salah satu upaya meningkatkan kepatuhan ibu hamil minum tablet besi.

\section{BAHAN DAN METODE}

Penelitian ini menggunakan desain observasional dengan pendekatan potong lintang. Lokasi penelitian adalah di Kabupaten Asahan dengan penentuan lokasi di kecamatan secara stratified random sampling. Setiap wilayah kecamatan digolongkan menurut cakupan K4, yaitu K4 lebih dari $85 \%$ dan K4 kurang dari atau sama dengan $85 \%$, sehingga diperoleh masing-masing 3 kecamatan untuk masing-masing kelompok.

Populasi dari penelitian ini adalah seluruh ibu hamil trimester II dan III di kecamatan terpilih. Subjek kemudian dipilih berdasarkan kriteria inklusi yaitu: ibu hamil yang diperiksa dan bertempat tinggal di wilayah kecamatan terpilih, tercatat dalam buku register ibu hamil di puskesmas, memiliki buku Kesehatan lbu dan Anak (KIA), mendapat tablet besi program, dan bersedia menjadi subjek. Kriteria eksklusinya yaitu: menderita suatu penyakit kronis (gangguan jantung, malaria, infeksi cacing), mempunyai komplikasi kehamilan, dan memeriksa kehamilan selain kepada bidan.

Jumlah subjek dalam penelitian ini adalah 202 orang yang terbagi dalam dua kelompok yaitu kelompok dengan cakupan K4 lebih dari 85\% dan kelompok dengan cakupan K4 kurang dari atau sama dengan $85 \%$. Penentuan jumlah subjek tersebut menggunakan ketentuan kesalahan tipe I dan II masing-masing sebesar $5 \%(Z \alpha=1,64)$ dan $20 \%$
$(Z \beta=0,84)$, proporsi ibu hamil dengan pelayanan ANC baik dan patuh minum tablet besi sebesar $17 \%$, risiko relatif pelayanan ANC tidak standar dibanding pelayanan standar sebesar 1,9 (11).

Data yang dikumpulkan meliputi beberapa aspek yang dilakukan mulai bulan Februari sampai dengan Mei 2007. Aspek penilaian pelayanan ANC dalam pengelolaan anemia ibu hamil digolongkan menjadi dua, yaitu pelayanan ANC baik (jika ibu hamil telah mendapat pelayanan meliputi pemeriksaan penentuan anemia, pemberian tablet besi, dan konsultasi gizi) dan pelayanan ANC tidak baik (jika hanya satu atau dua macam pelayanan yang diperoleh). Aspek pemeriksaan penentuan anemia dilakukan oleh bidan baik dengan cara pengukuran $\mathrm{Hb}$ (metode talquis atau sahli) atau hanya melihat gejala klinis pada kelopak mata yang disesuaikan dengan usia kehamilan ibu (12). Pemeriksaan dikatakan baik jika menggunakan kedua cara penilaian anemia dan dikatakan tidak baik jika hanya dilakukan satu macam penilaian anemia.

Aspek konsultasi gizi disampaikan oleh bidan yang berisi materi anemia, meliputi: pengertian, gejala, penyebab, akibat, manfaat tablet besi, cara minum tablet besi, efek samping tablet besi, dan sumber bahan makanan yang kaya zat besi (10). Konsultasi dikatakan baik jika ibu hamil menerima lebih dari atau sama dengan 6 materi konsultasi dan tidak baik jika ibu hamil menerima kurang dari 6 materi konsultasi. Pengetahuan anemia dikumpulkan dari pengujian terhadap materi konsultasi gizi yang diberikan bidan kepada ibu hamil yang dikelompokkan menjadi pengetahuan tinggi jika total nilai yang diperoleh lebih atau sama dengan nilai rata-rata pengetahuan seluruh subjek dan pengetahuan rendah jika total nilai yang diperoleh lebih kecil daripada nilai rata-rata pengetahuan seluruh subjek. Sikap tentang anemia dinilai berdasarkan respon ibu hamil terhadap pentingnya pencegahan anemia, digolongkan menjadi sikap baik jika total nilai yang diperoleh lebih atau sama dengan nilai ratarata seluruh subjek, dan sikap tidak baik jika total nilai yang diperoleh lebih kecil daripada nilai rata-rata seluruh subjek.

Kepatuhan minum tablet besi program diperoleh dengan menghitung jumlah selisih tablet besi yang tersisa dari total yang diberikan terakhir kali oleh bidan dihitung mulai dari tanggal tablet besi diberikan kepada ibu hamil sampai tanggal seharusnya tablet besi diminum (pengambilan data). Selain itu, untuk validasi informasi kepatuhan minum tablet besi hasil wawancara kepada ibu hamil, dilakukan uji Stool terhadap feses subjek (13). Ibu hamil dinilai patuh jika tablet besi yang diterima dari petugas kesehatan diminum lebih dari atau sama dengan 90\% dan hasil pemeriksaan Stool test (+), sedangkan ibu hamil dinilai tidak patuh jika tablet besi yang diterima dari petugas kesehatan diminum kurang dari $90 \%$ dengan hasil Stool test (-) atau (+) dan jika tablet besi yang diterima dari petugas kesehatan diminum lebih dari atau sama dengan $90 \%$ dengan hasil Stool test (-). 
Instrumen yang digunakan adalah kuesioner terstruktur (riwayat pelayanan ANC dalam pengelolaan anemia ibu, yang meliputi pertanyaan frekuensi pelayanan ANC, pemeriksaan penentuan anemia, konsultasi gizi, kepatuhan minum tablet besi, dan uji Stool terhadap feses ibu hamil) dan pengetahuan diukur menggunakan kuesioner dengan pertanyaan tertutup yang bersifat favourable dan unfavourable, sedangkan pengukuran sikap dilakukan dengan skala Likert. Analisis data bivariat menggunakan uji kai kuadrat dan analisis multivariat menggunakan uji regresi logistik untuk mengetahui hubungan antarvariabel.

\section{HASIL DAN BAHASAN}

\section{Karakteristik subjek penelitian}

Sebanyak $78,7 \%$ subjek berada pada usia kehamilan yang optimal (21-35 tahun) dan hanya $21,3 \%$ yang berada pada usia risiko tinggi untuk kehamilan. Selain itu, sebagian besar subjek bekerja sebagai karyawan swasta

Tabel 1. Distribusi karakteristik subjek

\begin{tabular}{|c|c|c|}
\hline Variabel & Jumlah (n) & Persentase (\%) \\
\hline \multicolumn{3}{|l|}{ Pendidikan terakhir } \\
\hline SD & 52 & 25,7 \\
\hline SLTP & 68 & 33,7 \\
\hline SLTA & 74 & 36,6 \\
\hline DIII/PT & 8 & 4,0 \\
\hline \multicolumn{3}{|l|}{ Jumlah anak } \\
\hline$\leq 2$ & 113 & 55,9 \\
\hline$>2$ & 89 & 44,1 \\
\hline \multicolumn{3}{|l|}{ Usia reproduksi (tahun) } \\
\hline $21-35$ & 159 & 78,7 \\
\hline$\leq 20$ dan $>35$ & 43 & 21,3 \\
\hline \multicolumn{3}{|l|}{ Pekerjaan ibu } \\
\hline Buruh & 50 & 24,8 \\
\hline Pedagang & 27 & 13,4 \\
\hline Petani & 52 & 25,7 \\
\hline Karyawan swasta & 65 & 32,2 \\
\hline \multicolumn{3}{|l|}{ Frekuensi ANC } \\
\hline$<4$ kali & 116 & 57,4 \\
\hline$\geq 4$ kali & 86 & 42,6 \\
\hline \multicolumn{3}{|l|}{ Usia ANC pertama kali } \\
\hline$<3$ bulan & 96 & 47,5 \\
\hline 3-6 bulan & 100 & 49,5 \\
\hline$>6$ bulan & 6 & 3,0 \\
\hline \multicolumn{3}{|l|}{$\begin{array}{l}\text { Persentase kepatuhan } \\
\text { minum tablet besi }\end{array}$} \\
\hline $\begin{array}{l}\text { Ibu hamil minum tablet } \\
\mathrm{Fe}<90 \%\end{array}$ & 77 & 38,1 \\
\hline $\begin{array}{l}\text { Ibu hamil minum tablet } \\
\mathrm{Fe} \geq 90 \%\end{array}$ & 125 & 61,9 \\
\hline \multicolumn{3}{|l|}{ Uji Stool } \\
\hline Positif & 99 & 49,0 \\
\hline Negatif & 103 & 51,0 \\
\hline
\end{tabular}

$(32,2 \%)$. Hal ini berarti secara biologis dan sosial ekonomi, subjek dapat dikatakan telah matang dan siap membangun kehidupan rumah tangga. Pada penelitian ini juga ditemukan sebanyak $47,5 \%$ subjek mulai memeriksakan kehamilan pada trimester pertama, namun subjek yang terbanyak $(49,5 \%)$ mulai memeriksakan kehamilannya pada trimester kedua. Kesadaran masyarakat terhadap manfaat pelayanan ANC dapat dikatakan rendah. Hal ini terlihat dari jumlah subjek yang melakukan kunjungan ANC lebih dari 4 kali hanya sebesar $42,6 \%$ (Tabel 1). Di Indonesia, kunjungan pelayanan ANC menurut Departemen Kesehatan RI adalah empat kali selama hamil, dengan pembagian satu kali pada kunjungan trimester pertama, satu kali pada trimester kedua, dan dua kali pada trimester ketiga. Tujuan pemeriksaan ini agar perkembangan keadaan ibu dan janin secara berkala dapat diketahui, sehingga adanya penyimpangan dapat diketahui sedini mungkin dan dikoreksi (14).

Selain itu, berdasarkan data yang dikumpulkan pada penelitian ini, terlihat sebagian besar subjek $(76,7 \%)$ mendapat pelayanan ANC dalam pengelolaan anemia yang tidak baik. Sedangkan sebesar $75,7 \%$ subjek mendapat pemeriksaan penentuan anemia kategori tidak baik, namun sebagian besar subjek $(87,6 \%)$ sudah mendapat konsultasi mengenai anemia secara baik dan diperoleh masing-masing sebanyak 51,5\% dan $68,3 \%$ subjek untuk kategori pengetahuan yang tinggi dan sikap yang baik mengenai anemia. Hal ini berpengaruh terhadap kepatuhan minum tablet besi yang sebagian besar juga tergolong baik $(61,9 \%)$ dan hasil uji Stool (-) diperoleh sebanyak 103 subjek $(51,0 \%)$.

Hubungan pelayanan ANC, pemeriksaan penentuan anemia, konsultasi gizi, pengetahuan, dan sikap subjek terhadap kepatuhan minum tablet besi

Hubungan pelayanan ANC, pemeriksaan penentuan anemia, konsultasi gizi, pengetahuan, dan sikap subjek terhadap kepatuhan minum tablet besi dapat dilihat pada Tabel 2. Berdasarkan tabel tersebut, pelayanan ANC, pemeriksaan penentuan anemia, konsultasi gizi, dan pengetahuan subjek memiliki hubungan yang bermakna dengan kepatuhan subjek minum tablet besi $(p<0,05)$, sedangkan sikap subjek ditemukan tidak memiliki hubungan bermakna dengan kepatuhan minum tablet besi.

Hubungan pelayanan ANC dengan kepatuhan minum tablet besi. Pelayanan ANC dalam pengelolaan anemia adalah serangkaian kegiatan pelayanan kepada ibu hamil yang meliputi pemeriksaan atau diagnosis anemia, pemberian tablet besi, dan konsultasi gizi. Ada beberapa penyebab ketidakpatuhan ibu hamil dalam minum tablet besi, antara lain petugas kesehatan yang memiliki kesadaran rendah terhadap pemeliharaan kehamilan, adanya anggapan bahwa tablet besi merupakan terapi pengobatan, dan tindak lanjut kunjungan ANC yang kurang baik (15). 
Tabel 2. Hubungan pelayanan ANC, pemeriksaan penentuan anemia, konsultasi gizi, pengetahuan, dan sikap dengan kepatuhan subjek dalam minum tablet besi

\begin{tabular}{|c|c|c|c|c|c|c|}
\hline \multirow[b]{2}{*}{ Variabel } & \multicolumn{2}{|c|}{ Kepatuhan subjek } & \multirow[b]{2}{*}{ Total } & \multirow[b]{2}{*}{$\begin{array}{c}\text { Rasio } \\
\text { prevalensi }\end{array}$} & \multirow[b]{2}{*}{ IK 95\% } & \multirow[b]{2}{*}{$\mathbf{p}$} \\
\hline & $\begin{array}{c}\text { Tidak patuh } \\
\text { n (\%) }\end{array}$ & $\begin{array}{l}\text { Patuh } \\
\text { n (\%) }\end{array}$ & & & & \\
\hline \multicolumn{7}{|l|}{ Pelayanan ANC } \\
\hline Tidak baik & $102(65,8)$ & $53(34,2)$ & 155 & 1,82 & $1,22-2,70$ & 0,001 \\
\hline Baik & $17(36,2)$ & $30(63,8)$ & 47 & & & \\
\hline \multicolumn{7}{|c|}{ Pemeriksaan penentuan anemia } \\
\hline Tidak baik & $101(66,0)$ & $52(34,0)$ & 153 & 1,79 & $1,22-2,64$ & 0,001 \\
\hline Baik & $18(36,7)$ & $31(63,3)$ & 49 & & & \\
\hline \multicolumn{7}{|l|}{ Konsultasi gizi } \\
\hline Tidak baik & $35(76,1)$ & $11(23,9)$ & 46 & 1,41 & $1,14-1,76$ & 0,012 \\
\hline Baik & $84(53,8)$ & $72(46,2)$ & 156 & & & \\
\hline \multicolumn{7}{|l|}{ Pengetahuan } \\
\hline Rendah & $68(69,4)$ & $30(30,6)$ & 98 & 1,42 & $1,12-1,79$ & 0,005 \\
\hline Tinggi & $51(49,0)$ & $53(51,0)$ & 104 & & & \\
\hline \multicolumn{7}{|l|}{ Sikap } \\
\hline Tidak baik & $42(65,6)$ & $22(34,4)$ & 64 & 1,18 & $0,93-1,48$ & 0,243 \\
\hline Baik & $77(55,8)$ & $61(44,2)$ & 138 & & & \\
\hline
\end{tabular}

Berdasarkan uji kai kuadrat diperoleh hubungan yang bermakna antara pelayanan ANC dalam pengelolaan anemia dengan kepatuhan subjek dalam minum tablet besi $(p=0,001$; rasio prevalensi $=1,82$; IK95\% $=1,22-2,70)$ (Tabel 2). Maka dapat diartikan bahwa, ibu hamil yang mendapat pelayanan ANC tidak baik mempunyai peluang 1,82 kali lebih tinggi untuk tidak patuh minum tablet besi dibandingkan ibu hamil yang mendapat pelayanan ANC baik.

Dengan demikian, ibu hamil yang tidak mendapat pelayananANC standar akan berakibat pada ketidakpatuhan minum tablet besi, yang pada akhirnya akan meningkatkan risiko terjadinya anemia. Lebih dari 50\% ibu hamil setelah mendapat penyuluhan mengerti akan manfaat tablet besi untuk mencegah anemia dan mereka patuh untuk mengonsumsi sampai habis tablet besi yang diterimanya (16).

Hubungan ini bisa menjelaskan bahwa pelayanan antenatal berperan dalam pencegahan dan memperbaiki pengaruh kegawatan dalam kehamilan. Pelayanan ANC yang baik dapat mendeteksi gejala dan tanda-tanda yang berkembang selama kehamilan, seperti anemia. Begitu pula sebaliknya, ibu hamil yang mendapat pelayanan kurang berkualitas tidak akan mendapat informasi tentang kesehatan ibu selama kehamilan.

Berdasarkan hasil yang diperoleh, terdapat sebesar $34,2 \%$ subjek yang mendapatkan pelayanan ANC tidak baik namun patuh dalam minum tablet besi. Hal ini memberi arti bahwa subjek dapat memperoleh informasi pelayanan ANC tidak saja saat melaksanakan kunjungan, tetapi dapat juga memperoleh informasi tentang manfaat pemeriksaan kehamilan dari tetangga, teman dekat, atau frekuensi berkomunikasi yang baik dengan kader pada saat datang ke posyandu. Selain itu, pengetahuan kesehatan keluarga atau teman dekat akan berpengaruh terhadap pengetahuan ataupun tindakan ibu hamil. Hal ini jawaban paling mendasar atas pendapat yang menyatakan adanya keterikatan individu dalam keluarga atau teman yang berpengaruh kuat terhadap keputusan individu dalam memanfaatkan pelayanan kesehatan terutama pelayanan ANC (17).

Hubungan pemeriksaan penentuan anemia dengan kepatuhan minum tablet besi. Pemeriksaan kehamilan dengan cara pendekatan risiko merupakan hal penting khususnya pada kehamilan risiko tinggi. Anemia sebagai salah satu faktor risiko tinggi perlu dideteksi sedini mungkin. Dengan demikian, pemeriksaan penentuan anemia merupakan keharusan yang dilakukan oleh bidan dalam melakukan pelayanan ANC. Sesuai dengan tugas pokok bidan desa, mereka harus dapat melakukan pelayanan ANC (14). Hasil uji statistik membuktikan adanya hubungan yang bermakna antara penentuan anemia dengan kepatuhan ibu hamil dalam minum tablet besi $(p=0,001$; rasio prevalensi $=1,79$; IK95\% $=1,22-2,64)$ (Tabel 2). Artinya ibu hamil dengan penentuan anemia yang tidak baik berisiko 1,79 lebih tinggi untuk tidak patuh minum tablet besi jika dibandingkan ibu hamil dengan cara penentuan anemia baik. Indikasi ini dapat memberi petunjuk kepada bidan dalam melakukan deteksi risiko kehamilan dan nasihat tentang anemia.

Berdasarkan hasil pengamatan pada penelitian ini, diketahui masih ada beberapa bidan yang tidak melakukan pemeriksaan anemia dengan alat ukur, karena alat ukur $\mathrm{Hb}$ tidak tersedia (habis) dalam paket bidan kit. Selain itu, ada beberapa bidan yang masih beranggapan bahwa pengukuran $\mathrm{Hb}$ akan menambah lama pemeriksaan ibu hamil. Dengan demikian, segala pelayanan yang diberikan oleh bidan tidak dipengaruhi oleh klien (subjek) karena kualitas pelayanan ANC berada di tangan pemberi pelayanan (bidan). Adanya keterbatasan kewenangan dan sarana yang dimiliki bidan tersebut, perlu diciptakan 
suasana keterbukaan dalam pelayanan dan saling merujuk di antara pemberi pelayanan agar ibu hamil tidak merasa dirugikan (18). Hasil penentuan $\mathrm{Hb}$ darah subjek sebenarnya merupakan indikator bagi bidan dalam memberikan pelayanan ANC, yaitu sebagai bahan untuk menjelaskan, agar pesan kesehatan lebih fokus terutama informasi mengenai manfaat tablet besi dan akibat yang ditimbulkan dari anemia.

Hubungan konsultasi gizi dengan kepatuhan minum tablet besi. Untuk meningkatkan kepatuhan minum tablet besi diperlukan media komunikasi dan peran aktif orang lain seperti suami ataupun anggota keluarga (19). Berdasarkan hasil uji kai kuadrat diperoleh adanya hubungan yang bermakna antara konsultasi gizi dengan kepatuhan ibu hamil dalam minum tablet besi $(p=0,012$; rasio prevalensi=1,41; IK95\%=1,14-1,76) (Tabel 2). Artinya ibu hamil yang mendapat konsultasi tidak baik mempunyai risiko 1,41 lebih tinggi untuk tidak patuh minum tablet besi jika dibandingkan ibu hamil yang mendapat konsultasi baik.

Rendahnya tingkat kepatuhan ibu hamil minum tablet besi disebabkan faktor lupa, takut bayi menjadi besar, kesadaran yang kurang mengenai pentingnya tablet besi dan ancaman bahaya anemia bagi ibu hamil dan bayi, serta adanya efek samping (mual atau pusing) yang ditimbulkan setelah minum tablet besi (5). Pada penelitian ini diperoleh sebanyak $41,1 \%$ subjek patuh dan $58,9 \%$ subjek tidak patuh minum tablet besi. Tujuh puluh tiga di antara 112 subjek $(65,2 \%)$ menyatakan tidak patuh karena lupa, 33 di antara 47 subjek (70,2\%) karena mual, 44 di antara 65 subjek $(67,7 \%)$ karena baunya tidak enak, dan 14 di antara 15 subjek $(93,3 \%)$ karena memiliki ketakutan bayi akan berukuran besar. Selain itu, diketahui pula penyebab rendahnya kepatuhan ibu hamil minum tablet besi karena adanya efek samping seperti mual dan pusing setelah minum tablet besi serta kurang paham tentang anemia dan manfaat tablet besi bagi diri ibu hamil $(20,21,22,23)$. Oleh karena itu, diperlukan penyampaian informasi yang jelas tentang manfaat tablet besi dan pengawasan yang rutin, sehingga dapat meningkatkan kepatuhan ibu hamil dalam minum tablet besi.

Metode konsultasi yang lebih mengedepankan pendekatan individu dianggap akan lebih efektif untuk meningkatkan pemahaman akan manfaat tablet besi, sehingga dapat meningkatkan motivasi pencegahan anemia (16). Selain metode, perlu juga memperhatikan alat penunjang konsultasi seperti leaflet atau lembar balik anemia dan manfaat tablet ibu hamil .

Hubungan pengetahuan dan sikap dengan kepatuhan minum tablet besi. Pengetahuan dan sikap subjek pada penelitian ini dinyatakan sebagai variabel pengganggu. Berdasarkan uji kai kuadrat diperoleh hubungan yang bermakna antara pengetahuan dengan kepatuhan subjek dalam minum tablet besi $(p=0,005$; rasio prevalensi=1,42; IK95\%=1,12-1,79) (Tabel 2). Maka dapat disimpulkan bahwa ibu hamil dengan pengetahuan rendah mempunyai peluang 1,42 lebih tinggi untuk tidak patuh minum tablet besi dibanding ibu hamil yang berpengetahuan tinggi.

Proporsi pengetahuan yang baik akan meningkatkan kepatuhan ibu hamil minum tablet besi. Kepatuhan minum tablet besi merupakan suatu bentuk perilaku yang dapat terwujud karena adanya pengetahuan yang diperoleh dari luar serta keyakinan dan adanya dorongan dari orang lain (petugas kesehatan, tetangga, atau teman dekat) (24). Agar tingkat kepatuhan ibu hamil lebih terjamin, selain dilakukan konsultasi juga perlu dilakukan pengawasan yang rutin (25). Hasil penelitian pada ibu hamil di Kabupaten Bantul tahun 2002 diperoleh adanya hubungan bermakna antara pengawasan suami dengan tingkat kepatuhan ibu hamil dalam minum tablet besi (23). Pengawasan minum tablet besi oleh suami dapat meningkatkan kemungkinan patuh hingga 8,5 kali lebih besar dibandingkan ibu hamil tanpa pengawasan dari suami (26). Hasil penelitian ini menemukan bahwa mayoritas subjek $(92,7 \%)$ menyatakan setuju apabila keluarga atau saudara selalu mengingatkan ibu hamil dalam minum tablet besi. Suami seharusnya menemani istri saat periksa ANC dan berkonsultasi dengan petugas kesehatan. Dengan demikian, keluarga atau suami juga ikut belajar mengenai gejala dan tanda-tanda komplikasi kehamilan. Calon suami yang memperoleh pendidikan antenatal dapat lebih meningkatkan frekuensi kunjungan ke klinik antenatal (27).

Sebanyak $65,6 \%$ subjek pada penelitian ini mempunyai sikap yang dikategorikan tidak baik dan tidak patuh minum tablet besi dan sebanyak 55,8\% subjek lainnya mempunyai sikap yang dikategorikan baik tetapi tidak patuh minum tablet besi. Berdasarkan uji kai kuadrat diketahui tidak ada hubungan antara sikap dengan kepatuhan ibu hamil dalam minum tablet besi $(p=0,243$; rasio prevalensi=1,18; IK95\%=0,93-1,48). Sikap yang rendah ini umumnya disebabkan kurangnya kesadaran mengenai pentingnya minum tablet besi dan ancaman bahaya anemia bagi ibu hamil dan bayi.

\section{Analisis multivariat}

Analisis multivariat digunakan untuk mengetahui hubungan variabel terikat dan variabel tergantung serta pengganggu, dengan menguji secara bersama-sama. Adapun variabel yang bermakna secara statistik dengan analisis bivariabel adalah yang mempunyai nilai $p$ kurang dari 0,25 . Analisis multivariat yang digunakan adalah model regresi logistik (Tabel 3).

Langkah selanjutnya adalah melakukan analisis regresi logistik lanjutan, yang dilaksanakan secara bertahap, yaitu dengan mengeluarkan variabel yang mempunyai nilai $\mathrm{p}$ yang paling besar dari analisis pada 
Tabel 3. Model regresi logistik hubungan pelayanan ANC dalam pengelolaan anemia dengan kepatuhan ibu hamil minum tablet besi dengan mengendalikan variabelvariabel pengganggu

\begin{tabular}{lccc}
\hline \multicolumn{1}{c}{ Variabel } & OR & CI 95\% & p \\
\hline $\begin{array}{l}\text { Pelayanan ANC dalam } \\
\text { pengelolaan anemia }\end{array}$ & 3,482 & $1,440-7,012$ & 0,262 \\
Penentuan anemia & 5,415 & $0,289-98,452$ & 0,254 \\
Konsultasi gizi & 1,405 & $0,937-2,206$ & 0,100 \\
Pengetahuan & 1,962 & $1,058-3,640$ & 0,032 \\
Sikap & 1,268 & $0,649-2,474$ & 0,487 \\
\hline
\end{tabular}

setiap tahapnya. Adapun hasil akhir dari analisis regresi logistik terlihat pada Tabel 4. Berdasarkan hasil akhir analisis regresi logistik diketahui pelayanan ANC dalam pengelolaan anemia dan pengetahuan secara bersamasama memiliki hubungan bermakna dengan kepatuhan ibu hamil dalam minum tablet besi $(p<0,05)$. Nilai OR pelayanan ANC yang diperoleh sebesar 3,125 (IK95\%= $1,562-6,251)$ yang berarti ibu hamil dengan pelayanan ANC yang tidak baik mempunyai peluang 3,125 kali lebih tinggi untuk tidak patuh minum tablet besi dibandingkan ibu hamil dengan pelayanan ANC baik setelah dikontrol variabel pengetahuan. Selain itu variabel pelayanan ANC dalam pengelolaan anemia pengaruhnya lebih besar jika dibandingkan pengetahuan terhadap kepatuhan ibu hamil minum tablet besi.

Tabel 4. Model hasil akhir regresi logistik hubungan pelayanan ANC dalam pengelolaan anemia dengan kepatuhan ibu hamil dalam minum tablet besi

\begin{tabular}{lccc}
\hline \multicolumn{1}{c}{ Variabel } & OR & IK 95\% & p \\
\hline $\begin{array}{l}\text { Pelayanan ANC dalam } \\
\text { pengelolaan anemia }\end{array}$ & 3,125 & $1,562-6,251$ & 0,001 \\
Pengetahuan & 2,153 & $1,189-3,896$ & 0,011 \\
\hline
\end{tabular}

\section{KESIMPULAN DAN SARAN}

Pada penelitian ini diperoleh adanya hubungan antara pelayanan ANC dalam pengelolaan anemia, pemeriksaan penentuan anemia, dan konsultasi gizi dengan kepatuhan ibu hamil minum tablet besi. Pelayanan ANC dalam pengelolaan anemia bersama-sama dengan pengetahuan berpengaruh terhadap kepatuhan ibu hamil dalam minum tablet besi, namun pelayanan ANC dalam pengelolaan anemia memiliki pengaruh yang lebih besar dibandingkan pengetahuan ibu hamil.

Berdasarkan kesimpulan di atas, disarankan kepada bidan desa agar dalam memberikan pelayanan ANC lebih aktif melakukan kunjungan kepada ibu hamil yang tidak aktif melakukan pemeriksaan ANC disertai pemberian konsultasi gizi, selain menunggu di poliklinik desa (polindes). Hal ini dimaksudkan agar pelayanan ANC lebih teratur dan berkesinambungan, sehingga ibu hamil merasa terawasi dan lebih paham akan manfaat tablet besi. Dinas Kesehatan juga diharapkan dapat lebih meningkatkan monitoring dan evaluasi secara rutin terhadap kelengkapan peralatan dalam penentuan anemia ibu hamil dan mewajibkan kepada setiap bidan untuk segera menyediakan sarana pengukuran $\mathrm{Hb}$ apabila persediaan telah habis. Dinas Kesehatan setempat juga sebaiknya menyediakan leaflet atau lembar balik anemia dan manfaat tablet ibu hamil sebagai media konsultasi gizi secara berkala, sehingga proses konsultasi akan lebih menarik, mudah dipahami, dan mudah diingat.

\section{Ucapan Terima Kasih}

Penulis mengucapkan terima kasih kepada subjek penelitian dan semua pihak yang telah membantu penelitian ini. Penulis juga menyampaikan terima kasih kepada kepala puskesmas, bidan koordinator, tenaga pelaksana gizi puskesmas, dan bidan desa di Puskesmas Mutiara, Gambir Baru, Binjai Serbangan, Hesa Air Genting, Sidodadi, dan Rawang yang telah memberikan izin dan fasilitas selama penelitian.

\section{RUJUKAN}

1. Departemen Kesehatan RI. Survei Kesehatan Rumah Tangga 2004. Dalam: Isniati. Efek suplementasi tablet $\mathrm{Fe}+$ obat cacing terhadap kadar hemoglobin remaja yang anemia di Pondok Pesantren Tarbiyah Islamiyah Pasir Kecamatan IV Angkatan Candung tahun 2008. J Sains Tek Far 2007; 12(2): 100-4.

2. Departemen Kesehatan RI. Manajemen [serial online] 2005 [cited 2007 Jan 11]. Available from: http://www. depkes.go.id

3. Hadi H. Editorial: Gizi lebih sebagai tantangan baru dan implikasinya terhadap kebijakan pembangunan kesehatan nasional. Jurnal Gizi Klinik Indonesia 2004; 1 (2): 51-8.

4. Rush D. Nutrition and maternal mortality in developing word. Am J Clin Nutr 2000; 72(Suppl): 212S-40S.

5. WHO. Major nutritional deficiency diseases in emergencis: the management of nutrition major emergencies. Jeneva: WHO; 2000.

6. Departemen Kesehatan RI. Pedoman pemberian tablet besi folat dan sirop besi bagi petugas. Jakarta: Direktorat Gizi Masyarakat Departemen Kesehatan RI; 1999.

7. Dinas Kesehatan Kabupaten Asahan. Profil kesehatan Kabupaten Asahan. Kabupaten Asahan: Dinas Kesehatan Kabupaten Asahan; 2006.

8. Departemen Kesehatan RI. Program penanggulangan anemia gizi pada WUS: strategi KIE program penanggulangan anemia gizi. Jakarta: Direktorat Gizi Masyarakat Departemen Kesehatan Rl; 2003.

9. Susetyo D, Hakimi M, Hadi H. Pengaruh suplementasi tablet Fe mingguan dan harian terhadap kepatuhan 
minum tablet Fe dan perubahan kadar hemoglobin pada ibu hamil di Kabupaten Bantul Yogyakarta. Jurnal Gizi Klinik Indonesia 2005; 2(2): 45-52.

10. Sandjaja, Hapsari D, Sudikno. Distribusi dan konsumsi pil besi untuk bumil di Indonesia 2005. Prosiding Temu IImiah dan Kongres PERSAGI XIII; 2005 Nov 21-24; Bali, Indonesia.

11. Dahlan MS. Besar subjek dalam penelitian kedokteran dan kesehatan. Jakarta: Arkans; 2005.

12. Departemen Kesehatan RI. Standar pelayanan kebidanan buku I. Jakarta: Departemen Kesehatan $\mathrm{RI} ; 2000$.

13. Afifi AM, Bennison RJ, Griffiths PD, Jenkins GC, McIntosh J, Russel IR. Simple test for ingested iron in hospital and domiciliary practice. Brit Med J 1966; 1:1021-2.

14. Departemen Kesehatan RI. Pedoman pelayanan antenatal care di tingkat pelayanan dasar. Jakarta: Depkes RI; 1995.

15. Winichagoon P. Prevention and control of anemia: Thailand experiences. J Nutr 2002; 132: 862S-6S.

16. Emawati F, Rosmalina Y, Herman S. Kebutuhan ibu hamil akan tablet besi untuk pencegahan anemia. Bogor: Pusat Penelitian dan Pengembangan Gizi dan Makanan; 2000.

17. Calhoun JF, Acocella JR. Psikologi tentang penyesuaian dan hubungan kemanusiaan. Satmoko RS (Alih Bahasa). Semarang: IKIP Semarang Press; 1990.

18. Bahri S. Analisis faktor-faktor yang berhubungan dengan kepatuhan bidan desa terhadap standar pelayanan antenatal di Dati II Bantul DIY [Tesis]. Yogyakarta: Universitas Gadjah Mada; 2000.
19. Triratnawati A. Upaya peningkatan kepatuhan ibu hamil dalam mengonsumsi pil tambah darah. Jurnal Epidemiologi Indonesia 1997; 2(3): 43-9.

20. Ekstrom EC, Kavishe FP, Habicht JP, Fronqillo EAJr, Rasmussen KM, Hemed L. Adherence to iron supplementation during pregnancy in Tanzania: determinants and hematologic consequences. Am J Clin Nutr 1996; 64(3): 368-74.

21. Schultink W, van der Ree M, Matulessi P, Gross R. Low compliance with an iron-supplementation program: a study among pregnant women in Jakarta, Indonesia. Am J Clin Nutr 1993; 57(2):135-9.

22. Yip R. Iron supplementation during pregnancy: is it efective?. Am J Clin Nutr 1996; 63: 853-5.

23. Widagdo D. Pengaruh suplementasi tablet Fe dengan supervisi suami pada ibu hamil terhadap umur kehamilan di Kabupaten Bantul. Jurnal Gizi Klinik Indonesia 2005; 2(1): 22-7.

24. Green LW, Kreuter MW. Health promotion planning an educational and environmental approach. second edition. London: Mayfield Publishing Company; 2000.

25. Susetyowati AN. Pengaruh supervisi bidan desa terhadap kepatuhan minum tablet besi dan perubahan kadar $\mathrm{Hb}$ ibu hamil di Kabupaten Bantul [Tesis]. Yogyakarta: Universitas Gadjah Mada; 2001.

26. Hadi H. Meningkatkan kepatuhan minum tablet besi ibu hamil: pentingnya peranan suami. Berita Kedokteran Masyarakat 2001; XVII(2): 51-62.

27. Ishak S, Lestari KW, Cut M. Keterlibatan suami dalam menjaga kehamilan istri di Puskesmas Kecamatan Kota Alam Banda Aceh. Buletin Penelitian Sistem Kesehatan 2005; 8(2): 100-5. 